\title{
Anti Ulcer Activity of Leea Indica in Wistar Albino Rats
}

\author{
Damayanthi Dalu* \\ Department Of Pharmacology, KL university, India
}

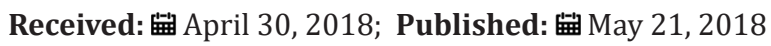

*Corresponding author: Damayanthi Dalu, KL college of pharmacy, KL deemed to be university, Guntur, India

\begin{abstract}
Objective: Leea indica is a well known plant with numerous pharmacological activities owing to the presence of the active constituents. Inspite of numerous therapeutic uses, efficacy of the plant in treating ulcers is not yet evaluated scientifically. Hence an attempt has been made to evaluate the Antiulcer activity of Leea indica.
\end{abstract}

Methods: The effect of Leea indica methanolic extract (LIME) on gastric ulcer in pylorus ligation-induced and aspirin induced models was studied by employing LIME at $200 \mathrm{mg} / \mathrm{kg}, 400 \mathrm{mg} / \mathrm{kg}$. In both the models Ranitidine (40mg/kg) was employed as the standard. Depending on the model, parameters evaluated were total acidity, free acidity, volume and pH of gastric fluid, ulcer score and percent inhibition of ulcer index.

Results: Data were analyzed following graph pad instat version 3.0 followed by Dunnets multiple comparision test. LIME $(400 \mathrm{mg} / \mathrm{kg})$ significantly $(\mathrm{P}<0.01)$ reduced gastric ulcer index in pylorus ligation-induced and Aspirin induced ulcer models comparable to that of Standard drug. Histopathological studies confirmed that LIME $(400 \mathrm{mg} / \mathrm{kg})$ possess anti ulcer activity in both models. The elicited activity might be owing to the existence of secondary metabolites such as flavonoids, tannins, and saponins.

Conclusion: Obtained results elucidate the Antiulcer activity of Leea indica methanolic extract. Further investigations on isolation of specific phyto chemicals and elucidating mechanisms of action are needed.

Keywords: Antiulcer, Pylorus Ligation Model, Aspirin Induced Model, Histopathology, Leea Indica; Peptic Ulceration; Vitaceae; Anti Hyper Lipidaemic; Antitumor; Hydrocarbons

\section{Mini Review}

Peptic ulceration is one of the common modern age epidemics affecting nearly $10 \%$ of world population [1]. Even though numerous potent anti-ulcer drugs are marketed, most of them were associated with toxicities, thus emphasizing the essentiality in search for new alternatives. Approximately $80 \%$ of the world's population trust on herbal-derived medicines reinforcing herbs was advantageous sources for new drugs. Leea indica a traditional Chinese medicine found to be distributed in India, Srilanka, Bangladesh, Burma, Nepal, Thailand, Laos, Camboida, China, Vietnam, New Guinea, Malasia, Solomon islands, North Australia, Santa Cruz island, New Hebrides and Fiji [2-4]. Leea indica, an evergreen large shrub of family vitaceae $[5,6]$ grows up to $8 \mathrm{mt}$. Leaflets are ovate-lanceolate with crenate to serrate margins. Leaves are 1-3 pinnate bearing 7 leaflets, with petioles $7-20 \mathrm{~cm}$ long. Fruits are purplish black, bearing six seeds with $1 \mathrm{~cm}$ in diameter. Flowers are greenish white with $5 \mathrm{~mm}$ across. Stems are glabrous to pubescent.

Leea indica leaves were scientifically evidenced for wide pharmacological activities like antitumor [7], antiviral [8], analgesic [9], sedative and anxiolytic [10], Nitric oxide inhibitory [11], phosphodiestrase inhibitory [12], antidiabetic [13]. Anti hyper lipidaemic [14]. Leaf decoction is employed in pregnancy and delivery for birth control and body pain $[4,15]$. Dried leaves ingested were effective against cancer [16]. Roasted leaves relieve vertigo. Leaves (31.4\%) constitute to be the most widely used parts in medicine preparation then fruits and roots (16.05\%) [17]. Therefore the current investigation was designed to screen the leaves for the antiulcer activity. Twenty three chemical constituents were detected in Leea indica leaves by Gc-Ms analysis, Spectroscopic 
techniques, and Co-TLC. Compounds identified were eleven hydrocarbons, palmitic acid, pthalic acid, 1-eicosanol,farnesol, soalnesol, gallic acid, three pthalic acid esters, lupeol, $\beta$-sitosterol and finally ursolic acid [18]. Though the plant was reported with numerous chemical constituents antiulcer activity was not yet screened. Hence the present study was taken up to investigate antiulcer activity of Leea indica.

\section{Materials and Methods}

\section{Chemicals}

Ranitidine(Lee Pharmaceuticals, Hyderabad.), Aspirin (Shalg pharmaceuticals, Goregaon, Mumbai.)

\section{Plant}

(Figure 1) Leea indica leaves were procured from Karthikavanam forest, Dhulapally, Hyderabad. These were authenticated by Dr. Madhavachetty, Professor, Sri Venkateshwara University, Tirupathi. The plant was placed in the college herbarium with a vocher specimen no. 438.

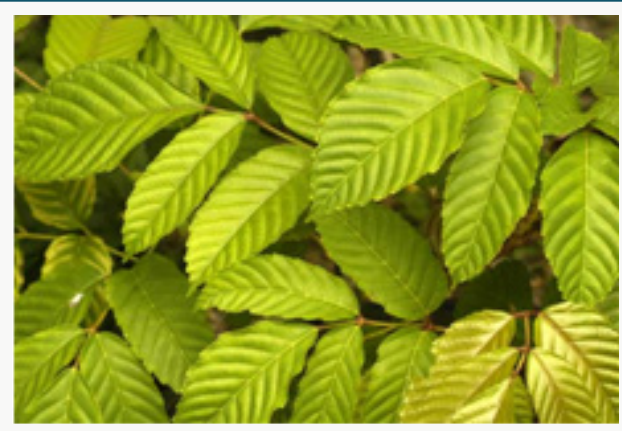

Figure 1: Leea indica leaves.

\section{Animals}

Male Wistar albino rats (200-250g) were purchased at Albino Research Center, Bachupally, Hyderabad. They were accomodatedin polypropylene cages with standard diet and water ad libitum. Experiment was designed as per ethical norms of CPCESA and IAEC Malla Reddy Institute of Pharmaceutical Sciences (1662/PO/a/12/ CPCSEA).

\section{Extraction}

Fresh leaves were shade dried, coarsely powdered and sieved with sieve no.40. Powdered material (500gm) was packed in soxhlet apparatus and subjected to extraction with methanol and water for about $48 \mathrm{~h}$. Solvents were evaporated under reduced pressure by rotary vacuum evaporator. Obtained methanolic extract (MELI) and aqueous extracts of Leea indica (AQLI) were subjected to phyto chemical screening and acute toxicity study [19].

\section{Acute Toxicity Study}

This study was performed as per OECD guideline 425 using limit test dose $2000 \mathrm{mg} / \mathrm{kg}$ [20]. Rats were fasted overnight and a limit dose of $2000 \mathrm{mg} / \mathrm{kg}$ was administered and observed for autonomic profiles (defecation and urination), behavioural profile (alertness, restlessness, irritability and fearfulness), neurologic profile (spontaneous activity, reactivity, touch response, pain response and gait), physical states such as lacrimation, loss of appetite, tremors, hair erection, salivation, diarrhoea and for morbidity or mortality continuously for $2 \mathrm{~h}$, periodically during the first $24 \mathrm{~h}$ and daily thereafter, for a total of $14 \mathrm{~d}$.

\section{Antiulcer Activity}

Pylorus Ligation Method: Male Wistar albino rats were segregated into four groups comprising five each [21]. Group I negative control, received distilled water, Group II positive control, received ranitidine 50mg/kg; Group III LIME (200mg/kg, p.o); Group IV LIME (400mg/ $\mathrm{kg}, \mathrm{p} . \mathrm{o})$. Plant extracts were administered for $10 \mathrm{~d}$. At the end of experimental period rats were fasted overnight with water ad libitum. Standard, Ranitidine (40mg/kg) and LIME $(200,400 \mathrm{mg} /$ $\mathrm{kg}$ ) were administered. Under light ether anaesthesia, the abdomen was cut opened by incision below the xiphoid process. The Pylorus end of stomach was slightly lifted up and ligated avoiding damage to blood vessels. After completing ligation stomach was replaced and the abdominal wall is sutured and closed. Rats were deprived of water during post operative period for 3 to $4 \mathrm{~h}$ [22]. Four hours later, stomach was dissected out. Stomach contents were drained into tubes and were subjected to centrifugation at $2000 \mathrm{r} / \mathrm{m}$ for 10 min. Supernatant obtained was analysed for gastric volume, $\mathrm{pH}$, free acidity and total acidity. The stomach was incised along the greater curvature, and observed for ulcers and the ulcer index (UI) was calculated. Ulcers were scored and severity was assessed microscopically $(10 \mathrm{X})$ employing hand lens (10 X). The scores were given as mentioned.

$$
\begin{aligned}
& 0=\text { normal stomach. } \\
& 0.5=\text { red coloration. } \\
& 1.0=\text { spot ulcers. } \\
& 1.5=\text { hemorrhagic streaks. } \\
& 2.0=\text { ulcer }>3 \text { but }<5 . \\
& 3.0=\text { ulcer }>5
\end{aligned}
$$

The ulcerated area and the total mucosal area were calculated. Ulcer index (UI) was determined as

Ulcer Index $=10 \mathrm{x} \mathrm{X}$; where $\mathrm{X}=$ total mucosal area/total ulcerated area.

$\%$ Ulcer protection $=\{($ UI of control- UI of test $) \times 100\} /$ UI of control

\section{Determination of Free Acidity And Total Acidity}

One $\mathrm{ml}$ of gastric juice was pipetted into $100 \mathrm{ml}$ conical flask. To these 2 to 3 drops of topfer's reagent was added and titrated with $0.01 \mathrm{~N} \mathrm{NaoOH}$ until red colour disappears and the colour turns to yellowish orange. The volume of the alkali added was noted. Obtained volume corresponds to free acidity. Now 2 to 3 drops of 
phenolphthalein solution was added and titration was continued until red tinge reappear. Total volume of alkali added was noted. This volume corresponds to total acidity. Acidity = Volume of $\mathrm{NAOH}$ x Normality / $100_{\text {meq } / 1.0}$

\section{Aspirin induced model}

Wistar albino rats were segregated into four groups comprising five each. Group I negative control, received Aspirin (200mg/kg, p.o); Group II Standard, Ranitidine (40mg/kg, p.o); Group III LIME (200mg/kg p.o); Group IV LIME (400mg/kg p.o). Standard, Ranitidine $(40 \mathrm{mg} / \mathrm{kg})$ and LIME $(200,400 \mathrm{mg} / \mathrm{kg})$ were administered for 10d. Rats were fasted overnight Aspirin (200mg/ $\mathrm{kg})$, Ranitidine $(40 \mathrm{mg} / \mathrm{kg})$ and LIME $(200,400 \mathrm{mg} / \mathrm{kg})$ were administered. $4 \mathrm{~h}$ later rats were sacrificed. Stomach was then excised along the greater curvature and examined for ulcers and the ulcer index (UI) was calculated [23-25].
a) $0=$ normal stomach.
b) $\quad 0.5=$ red coloration.
c) $1.0=$ spot ulcers.
d) $1.5=$ hemorrhagic streaks.
e) $2.0=$ ulcer $>3$ but $<5$.

\section{f) $3.0=$ ulcer $>5$}

The ulcerated area and the total mucosal area were calculated. Ulcer index (UI) was determined as

Ulcer Index $=10 \mathrm{xX}$; where $\mathrm{X}=$ total mucosal area/total ulcerated area. $\%$ Ulcer protection $=\{($ UI of control- UI of test $) \times 100\} /$ UI of control.

\section{Histopathological Evaluation}

The stomachs were immersed in $10 \%$ formalin solution for histopathological examination. These tissues were processed, embedded in paraffin wax. The central part of damaged or ulcerated tissue (if present) was cut on half along the greater curvature. If the damage is not seen then sections of $5 \mu \mathrm{m}$ thickness were cut by a rotary microtome and stained with haematoxylin and eosin. Stained sections were examined under microscope for histopathological changes such as congestion, haemorrhage, necrosis, inflammation, infiltration, erosion and ulcer.

\section{Statistical Analysis}

Results were expressed as mean \pm SEM. Statistical analysis was done by using Graph pad instate version 3 followed by Dunnet's $t$ test. Values of $\mathrm{P}$ less than $<0.05$ were considered as statistically significant (Tables 1-4) and (Figures 1-3).

Table 1: Phytochemical screening of Leea indica.

\begin{tabular}{|c|c|c|}
\hline Phyto Constituents & Methanolic Extract & Aqueous Extract \\
\hline Carbohydrates & + & - \\
Proteins & + & + \\
Flavonoids & + & + \\
Steroids & + & - \\
Tannins & + & + \\
Phenolics & + & - \\
Saponins & - & - \\
Cardiac glycosides & - & - \\
Starch & + & - \\
Alkaloids & - & - \\
Glycosides & & + \\
\hline
\end{tabular}

+ve - Present; -ve - Absent

Table 2: Effect of LIME on gastric secretion in pylorus ligation induced ulceration in rats.

\begin{tabular}{|c|c|c|c|c|c|}
\hline S. No & Treatment & $\begin{array}{c}\text { Vol of Gastric Juice } \\
\text { (ml) }\end{array}$ & Free Acidity & Total Acidity & Ph \\
\hline & Control + Pylorus & $6.86 \pm 0.13$ & $84.10 \pm 3.12$ & $115.21 \pm 2.42$ & $1.42 \pm 0.51$ \\
I & ligation & $2.33 \pm 1.12^{*}$ & $35.25 \pm 2.44^{* *}$ & $42.62 \pm 1.16^{* *}$ & $6.7 \pm 0.18^{* *}$ \\
II & Ranitidine (40mg/kg) & $4.02 \pm 0.65^{\text {ns }}$ & $77.56 \pm 3.2 \mathrm{~ns}$ & $106.72 \pm 2.53 \mathrm{~ns}$ & $2.81 \pm 0.30^{*}$ \\
IV & MELI (200mg/kg) & $2.86 \pm 0.81^{*}$ & $35.8 \pm 1.98^{* *}$ & $47.34 \pm 1.98^{* *}$ & $6.60 \pm 0.25^{* *}$ \\
\end{tabular}

mean \pm S.E.M. ${ }^{*} \mathrm{P} 0.05,{ }^{* *} \mathrm{P}<0.01$ compared with Control. 
Table 3: Effect of LIME on ulcer index and \% protection in pylorus ligation induced ulceration in rats.

\begin{tabular}{|c|c|c|c|}
\hline S.No & Treatment & Ulcer index & \% protection \\
\hline I & Control + Pylorus ligation & $6.44 \pm .0 .71$ & - \\
II & Ranitidine (40mg/kg) & $1.8 \pm 0.69^{* *}$ & 72.04 \\
III & MELI (200mg/kg) & $6.1 \pm 0.55^{\text {ns }}$ & 7.20 \\
IV & MELI (400mg/kg) & $1.73 \pm 0.42^{* *}$ & 73.13 \\
\hline
\end{tabular}

Mean \pm S.E.M. ${ }^{*} \mathrm{P}<0.05 \&{ }^{* *} \mathrm{P}<0.01$ when compared with Control.

Table 4: Effect of LIME on ulcer index and \% protection in Aspirin induced ulceration in rats.

\begin{tabular}{|c|c|c|c|}
\hline S.No & Treatment & Ulcer index & \% Protection \\
\hline I & Control + Aspirin & $7.45 \pm 0.54$ & 74.49 \\
II & Ranitidine $(40 \mathrm{mg} / \mathrm{kg})$ & $1.95 \pm 0.34^{* *}$ & 29.53 \\
III & MELI $(200 \mathrm{mg} / \mathrm{kg})$ & $5.25 \pm 0.84^{*}$ & 77.85 \\
IV & MELI $(400 \mathrm{mg} / \mathrm{kg})$ & $1.65 \pm 0.12^{* *}$ & \\
\hline
\end{tabular}

mean \pm S.E.M. *P $0.05,{ }^{* *} \mathrm{P}<0.01$ when compared with Control.

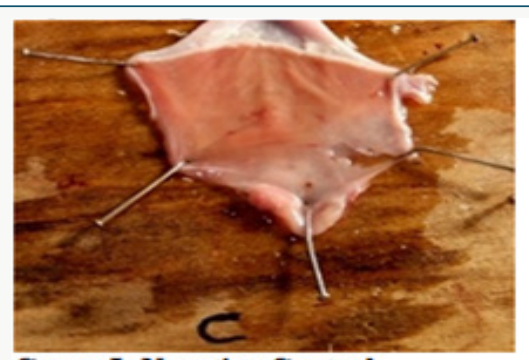

Group I: Negative Control

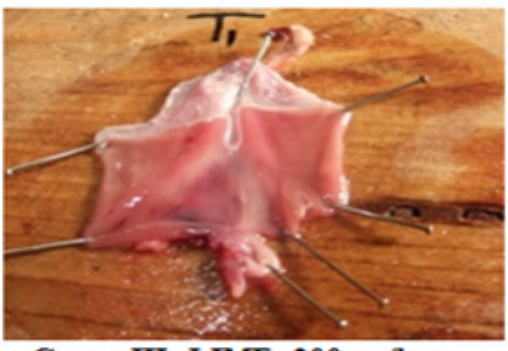

Group III: LIME $-200 \mathrm{mg} / \mathrm{kg}$

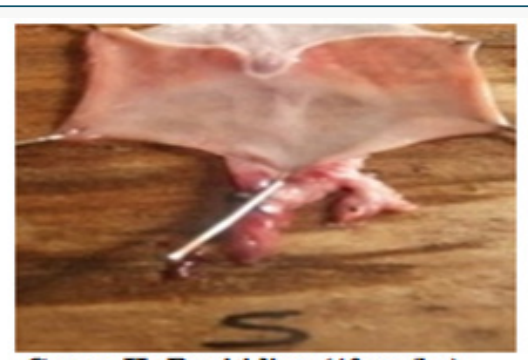

Group II: Ranitidine $(40 \mathrm{mg} / \mathrm{kg})$

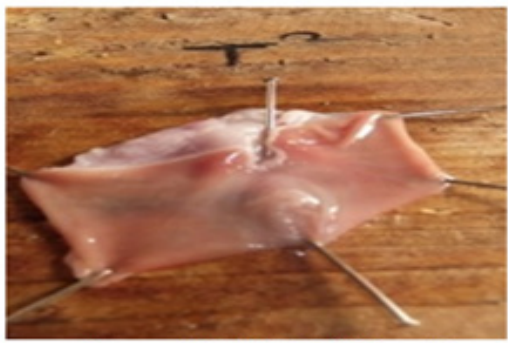

Group IV: LIME-400mg/kg

Figure 2: Pylorus ligation method

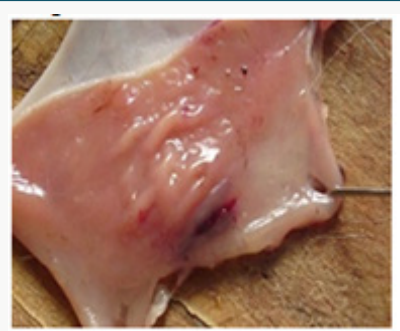

Group I: Control Aspirin (200 mg/kg)

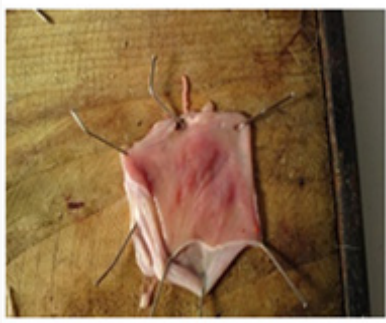

Group III: LIME -200mg/kg

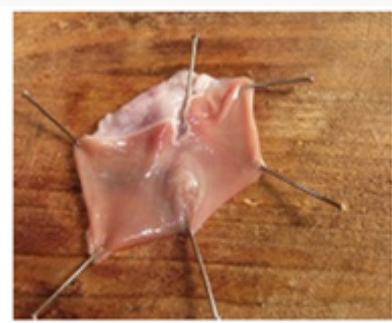

Group II: Ranitidine (40mg/kg)

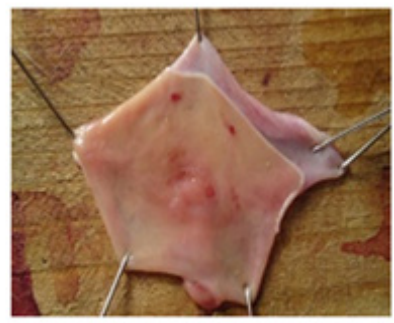

Group IV: LIME-400mg $/ \mathrm{kg}$

Figure 3: Aspirin induced method 


\section{Results}

Phytochemical screening of methanolic extract of Leea indica revealed the existence of phyto constituents like carbohydrates, flavonoids, steroids, tannins, phenols, saponins and alkaloids. Aqueous extract of Leea indica is constituted with phyto contituents like carbohydrates, flavonoids, phenols and alkaloids. In acute toxicity studies MELI was found to be nontoxic upto $2000 \mathrm{mg} / \mathrm{kg}$ b.wt. Hence $1 / 10^{\text {th }}, 1 / 5^{\text {th }}$ of dose was selected for further pharmacological screening. In pylorus ligated ulcer model Ranitinde (40mg $/ \mathrm{kg}$ ) and MELI ( $400 \mathrm{mg} / \mathrm{kg}$ ) produced a significant decrease in volume of gastric acid $(\mathrm{P}<0.05)$, free acidity $(\mathrm{P}<0.05)$, total acidity $(\mathrm{P}<0.01)$ and increase in $\mathrm{pH}(\mathrm{P}<0.01)$. MELI $(200 \mathrm{mg} /$ $\mathrm{kg}$ ) did not produce significant decrease in volume of gastric acid, free acidity, total acidity. MELI $(400 \mathrm{mg} / \mathrm{kg}$ ) produced a greater decrease in UI compared to standard $(40 \mathrm{mg} / \mathrm{kg})$. In aspirin induced ulcer model Ranitidine $(40 \mathrm{mg} / \mathrm{kg}$ ) and MELI $(400 \mathrm{mg} / \mathrm{kg}$ ) produced a significant decrease $(\mathrm{P}<0.01)$ in volume of gastric acid $(\mathrm{P}<0.05)$, free acidity $(\mathrm{P}<0.05)$, total acidity $(\mathrm{P}<0.01)$ and increase in $\mathrm{pH}(\mathrm{P}<0.01)$. MELI $(400 \mathrm{mg} / \mathrm{kg})$ produced a greater decrease in UI compared to standard $(40 \mathrm{mg} / \mathrm{kg})$. Ulcers characterised by redness, hemorrhagic stripes and the damage of mucosal layer were observed in negative control group, in both pylorus ligated ulcer model and in aspirin induced ulcer model. Rats administered with MELI $(400 \mathrm{mg} / \mathrm{kg})$ and the standard drugs ranitidine $(40 \mathrm{mg} /$ $\mathrm{kg}$ ) showed reduced redness and mucosal uniformity.

\section{Discussion}

Although numerous drugs were available for gastric ulcers adverse reactions like gynecomastia, hematopoietic changes, acute interstitial nephritis [26], thrombocytopenia [27], anaphylaxis reactions [28], nephrotoxicity and hepatotoxicity [29] limits the use. Therefore potent and safe herbs with lesser side effects were better alternatives for gastric ulcer. Herbs with reported antiulcer activity possess active constituents like saponins, flavonoids in considerable amounts. Owing to the existence of phyto constituents like carbohydrates, flavonoids, steroids, tannins, phenols, saponins and alkaloids methanolic extract is subjected to further pharmacological screening. Saponins were proposed to act by activation of mucosal protective factors [30]. Tannins elicit activity by tanning the mucosal layer and rendering it less permeable and more resistant to chemical and mechanical injury or irritation [31]. Flavonoids act probably by increasing prostaglandin secretion of mucosal layer and reducing the deleterious effects of free radicals. Leea indica might have elicited antiulcer activity owing to the presence of saponins, flavonoids and tannins. According to Acute toxicity study the plant extract was found to be safe upto $2000 \mathrm{mg} /$ $\mathrm{kg}$. Hence the doses selected for the study was $1 / 5^{\text {th }}$ and $1 / 10^{\text {th }}$ of the toxic dose $200 \mathrm{mg} / \mathrm{kg}, 400 \mathrm{mg} / \mathrm{kg}$. The pylorus ligated ulcer model is reproducible and more predictable model to screen antiulcer drugs. In this model ulcers are accomplished owing to auto digestion of mucus by accumulated gastric juice, decreased mucosal blood flow, and breakdown of the mucosal barrier [32]. This model has an added advantage of endogenous ulcer development neither by utilizing exogenous ulcerogens nor inducing exogenous interfering factors for producing ulcers. Plant extract might have elicited antiulcer activity either by decreasing gastric acid secretion or increasing mucus production proving its antisecretory effect [33]. Aspirin inhibit cyclo-oxygenase enzyme thereby inhibiting prostaglandin (PGs) synthesis. Prostaglandins $\left(\mathrm{PGE}_{2} \& \mathrm{PGI}_{2}\right)$ possess antiulcer activity by stimulating the secretion of mucus and bicarbonate, causing vasodilatation and inhibiting acid secretion [34]. Antiulcer activity of Leea indica might be by mucosal protective effect may be due to the biosynthesis of prostaglandins. Histopathological studies reveal the protective effect of MELI $(400 \mathrm{mg} / \mathrm{kg}$ ) against ulcers induced by pyloric ligation and aspirin induced model. Higher dose of MELI $(400 \mathrm{mg} / \mathrm{kg}$ ) elicited greater antiulcer effect compared to MELI (200mg/kg). Marked response was seen in standard group.

\section{Conclusion}

In conclusion, obtained experimental results elucidate Antiulcer activity of Leea indica in pylorus ligation method and aspirin induced method. MELI $(400 \mathrm{mg} / \mathrm{kg})$ elicited greater activity compared to standard. Increased efficacy and reduced side effects of herbal drugs compared to modern drug give increase prominence. Histopathology studies clearly evidenced antiulcer activity of Leea indica. Existence of Phytochemical constituents might have contributed to the elicited activity. Further isolation of active constituents and elucidating their mechanism gives a better antiulcer drug with lowered toxicities.

\section{References}

1. Soll AH Peptic ulcer and its complications (Eds) (1998) Sleisenger M, Feldman M, Scharschmidt BF. Philadelphia: Saunders Company, Gastrointest Liver Dis p. 620.

2. Ridsdale CE (1974) A revision of the family Leeaceae. Blumea 22(1): 57100.

3. Ridsdale CE (1976) Leeaceae. Flora Malesiana. Series 1(7): 775-782.

4. Saralamp P (1997) Medicinal plants in Thailand. Department of Pharmaceutical Botany, Faculty of Pharmacy, Mahidol University, Bangkok, Thailand: 2.

5. Stevens PF (2001) onwards, Angiosperm phylogeny website, Version 9, June 2008 (and more or less continuously updated since.

6. Angiosperm phylogeny Group (APG) (2003) An update of the Angiosperm Phylogeny Group classification for the orders and families of flowering plants: APG II, Bot J Linnean Soc 141(4): 399-436.

7. Obayed RaihanMd, Mohammed Tareq Syed, Mohammed, Afrina Brishti, Kursad Alam Md, et al. (2012) Amer J Biomed sci 4(2): 143-152.

8. Abdul manaf Ali, Muhammad mukrammackeen, Saleh H, Elsharkawy, Junainah A Hamid, et al. (1996) Antiviral and cytotoxic activities of some plants used in Malaysian indigenous medicine Pertanika J Trop Agric Sci 19(3): 129-136.

9. Talha Bio Emran, Atiar Rahman Md, Zahid Hose SM, Mominur Rahman Md. Phytopharmacol (2012) 3(1): 150-157.

10. Obayed Raihan Md, Mohammed Tareq Syed, Afrina Brishti, Kursad Alam Md, Haque Anamul, Sekendar Ali Md (2011) Evaluation of Antitumor Activity of (Burm.f.) Merr. Extract against Ehrlich Ascites Carcinoma (EAC) Bearing Mice. Leea indica Drug discoveries and Therap 5(4): 185189. 
11. Saha K, Lajis NH, Israf DA, Hamzah AS, Khoziroh S, et al. (2004) Evaluation of antioxidant and nitric oxide inhibitory activities of selected Malaysian medicinal plants. J Ethanopharma 92(3): 263-267.

12. Prapapan Temkitthawon P, Viyoch J, Limpeanchob N, Pongamornkul W, Sirikul C, (2008) Screening for phosphodiesterase inhibitory activity of Thai medicinal plants. J Ethanopharma 119(2): 214-217.

13. Damayanthi D, Satyavati D, Suresh A (2014) Antihyperglycemic and Hypolipidemic activity of Leea indica. Int J Bioassays 3(3): 3155-3159.

14. Damayanthi D, Satyavati D (2016) A ntihyperlipidemic activity of Hydroalcoholoic extracts of selected plants in high fat diet fed rats. Adv Pharmacol Toxicol 17(1): 65-82.

15. Graham JG, Quinn ML, Fabricant DS, Fransworth NR (2000) Plants used against cancer - an extension of the work of Jonathan Hartwell. J Ethanopharma 73(3): 347-377.

16. Bourdy G, Walter A (1992) Maternity and medicinal plants in Vanuatu I. The cycle of Reproduction. J Ethanopharma 37(3): 179-196.

17. Shanmugan S, Annadurai M and Rajendran K (2011) Ethano medicinal plants used to cure diarrhoea and dysentery in pachalur hills of dindigul district in Tamilnadu, Southern India. Indian J Applied Pharma Sci 1(8): 94-97.

18. GV Srinivasan, choorikkat Ranjith, Kochukaratu Krishnan Vijayan (2008) Identification of chemical compounds from the leaves of Leea indica. Acta pharm 58(2): 207-214.

19. Kokate CK (1994) Practical Pharmacognosy. Delhi: VallabhPrakashan. In An $\left(4^{\text {th }}\right.$ Edn).

20. OECD guidelines for testing of chemicals. Acute oral toxicity. Up and Down Procedure. Adopted 17th December 2001.

21. SarmisthaSaha, GaganGoswami (2010) Study of antiulcer activity of Ficusreligiosa L. on experimentally induced gastric ulcers in rats. Asian Pacific J Trop Med, pp. 791-793.

22. Muniappan M, Sundararaj T (2003) Anti-inflammatory and antiulcer activities of Bambusaarundinacea. J Ethnopharmacol 88(3): 161-167.
23. Parmar NS, Desai JK (1993) A review of current methodology for the evaluation of gastric and duodenal antiulcer agents. Indian J Pharmacol 25(3): 120-135.

24. Perera LM, Ruedas D, Gómez BC (2001) Gastric antiulcer effect of Rhizophora mangle LJ Ethnopharmacol 77(1): 1-3.

25. Ganguly AK (1969) A method for quantitative assessment of experimentally produced ulcers in the stomach of albino Rats. Specialia Experientia 25(11): 1224.

26. Ra A, Tobe SW (2004) Acute interstitial nephritis due to pantoprazole. Ann Pharmacother 38(1): 41-45.

27. Zlabek JA, Anderson CG (2002) Lansoprazole induced thrombocytopenia. Ann Pharmacother 36(5): 809-811.

28. González P, Soriano V, López P, Niveiro E (2002) Anaphylaxis to proton pump inhibitors. Allerg Immunopathol 30(6): 342-343.

29. Fisher AA, Couteur DG (2001) Nephrotoxicity and hepatotoxicity of histamine $\mathrm{H}_{2}$ receptor antagonists. Drug Saf 24(1): 39-57.

30. Satio H, Lee YM, Takagi K, Shoji S, Kondo N (1977) Pharmacological studies of Panacis japonica rhizome Int J Chem Pharmaceut Bull 25(5): 1017-1025.

31. Asuzu IU, Onu OU (1990) Anti-ulcer activity of the ethanolic extract of Combretum dolicopetalumroot. Int J Crude Drug Res 28(1): 27-32.

32. Goel RK, Bhattacharya SK (1991) Gastroduodenal mucosal defence and mucosal protective agents. Indian J Exp Biol 29(8): 701-714.

33. Devaraj VC, Mohammad A, Satya P (2007) Effect of leaves and fruits of Moringa oleifera on gastric and duodenal ulcers. Pharm Biol 45(4): 332338.

34. Satoskar RS, Nirmala NR, Bhandarkar SD (2011) Pharmacol and Pharmacother. $20^{\text {th }}(E d n)$, Popular Prakashan private limited 163: 621626.

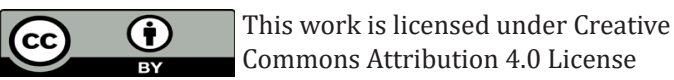

To Submit Your Article Click Here:

Submit Articl

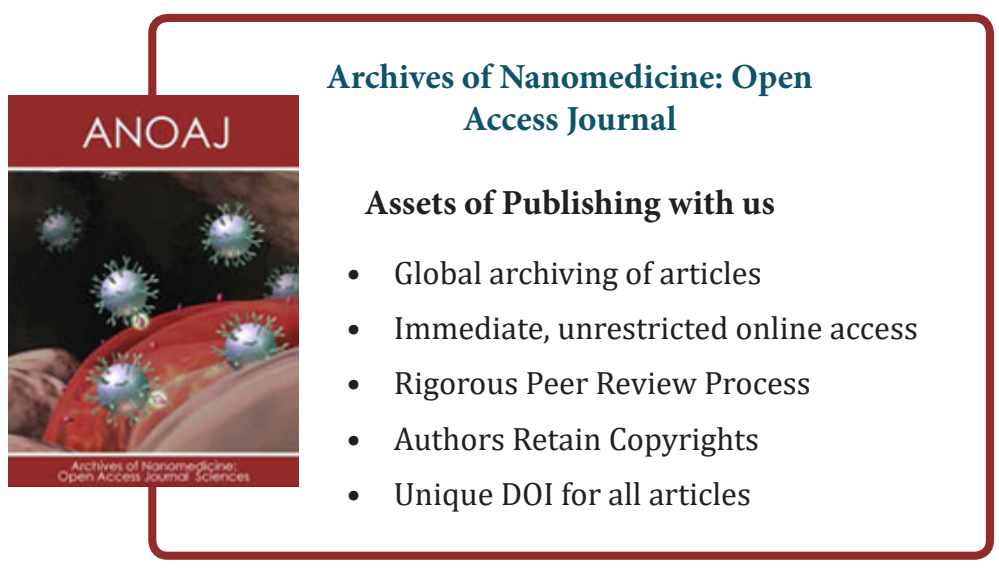

